\title{
Integrated Cooling Systems for Passenger Vehicles
}

\author{
Brace CJ, Burnham-Slipper H, Wijetunge RS, Vaughan ND*, Wright K, Blight $\mathrm{D}^{\#}$ \\ *University of Bath "Airtex Products Ltd
}

Copyright $\odot 2001$ Society of Automotive Engineers, Inc.

\begin{abstract}
Electric coolant pumps for IC engines are under development by a number of suppliers. They offer packaging and flexibility benefits to vehicle manufacturers. Their full potential will not be realised, however, unless an integrated approach is taken to the entire cooling system.

The paper describes such a system comprising an advanced electric pump with the necessary flow controls and a supervisory strategy running on an automotive microprocessor. The hardware and control strategy are described together with the simulation developed to allow its calibration and validation before fitting in a B/C class European passenger car. Simulation results are presented which show the system to be controllable and responsive to deliver optimum fuel consumption, emissions and driver comfort.
\end{abstract}

\section{INTRODUCTION}

The benefits of advanced cooling systems are well documented [1,2] and include -

- Cooling capacity is not engine speed dependant

- Reduced warm up times

- Enhanced cabin heater control

- Run on capability

- Power saving

- No cavitation

- Less block machining

- Simplified belt runs

- Potentially reduced engine length

- Fuel economy

- Emissions

- Less undesired cycling of engine temperature

- Pro-active cooling regime for hard acceleration

- Flexible positioning of components

- Easier service replacement
Progress is already apparent in the area of reduced coolant flow rate. Conventional cooling needs on smaller engines with mechanically driven water pumps vary between 2.0 to $2.6 \mathrm{~L} / \mathrm{min} / \mathrm{kW}$. Some advanced engines already run at $1.0-1.7 \mathrm{~L} / \mathrm{min} / \mathrm{kW}$. It is predicted that with an electric pump \& diverter valve with precision cooling \& nucleate boiling sensing \& control, flows under 1.0 $\mathrm{L} / \mathrm{min} / \mathrm{kW}$ would be achievable. Many engines already rely on nucleate boiling during high load conditions although the precise control required to fully utilize the technique requires an advanced cooling system [3,4]. To investigate the potential for such systems a prototype vehicle was fitted with an electrically driven water pump and compared with a conventional mechanically driven pump for a base line comparison.

Tens of thousands miles of mixed road driving and chassis dynamometer data have been collected from the first prototype vehicle. Trailer loads and long inclines were simulated on chassis dynamometer tests. All road testing was conducted with a normal passenger load. As predicted, the electric pump ran at minimum speed under normal driving conditions. The pump increased speed for short periods on 'heat soak' after motorway driving, extended 'idle' in hot conditions and during extreme hill climbs.

Most of the information was as predicted, but there some problems with the cooling system. The thermostat was relatively slow to respond. Under certain 'open thermostat' conditions the heater matrix was not always receiving sufficient flow. System pressure, an important factor when designing against cavitation, was rarely as high as desired. This is a common finding on vehicles which use de-gas bottle air compression to regulate system pressure. It was concluded that electronic control over the flow diverter valve was essential if the optimum system performance was to be achieved.

Analysis of the data from the first vehicle has yielded design information for a second prototype vehicle. This test car is fully instrumented with an EMU controlled 
electric pump and flow diverter valve. There is a dual 12/42-voltage system and 25 channels of data logged with a real time display. Base line testing was conducted against the mechanical pump and augmented with information provided by the vehicle manufacturer. Due to the circuitry of the cooling system, flow is monitored by two separate flow meters. Following chassis dynamometer testing at Bath University an extensive road test program is scheduled. A similar program using a larger test vehicle is also in progress.

\section{HARDWARE DESIGN}

VEHICLE - The vehicle selected was a Ford Focus with a 1.6L gasoline engine. The coolant circuit layout of the chosen demonstrator vehicle was maintained where possible as shown schematically in Figure 1. The major components added were the pump-motor assembly with its associated power electronics and the flow control valve. The pump motor assembly was located between radiator outlet and cylinder block inlet. The mechanical pump housing with the impeller removed was retained as it was integrated with the cylinder block casting. The flow control valve was fitted in line between the engine and radiator inlet. The wax pellet thermostat was removed.

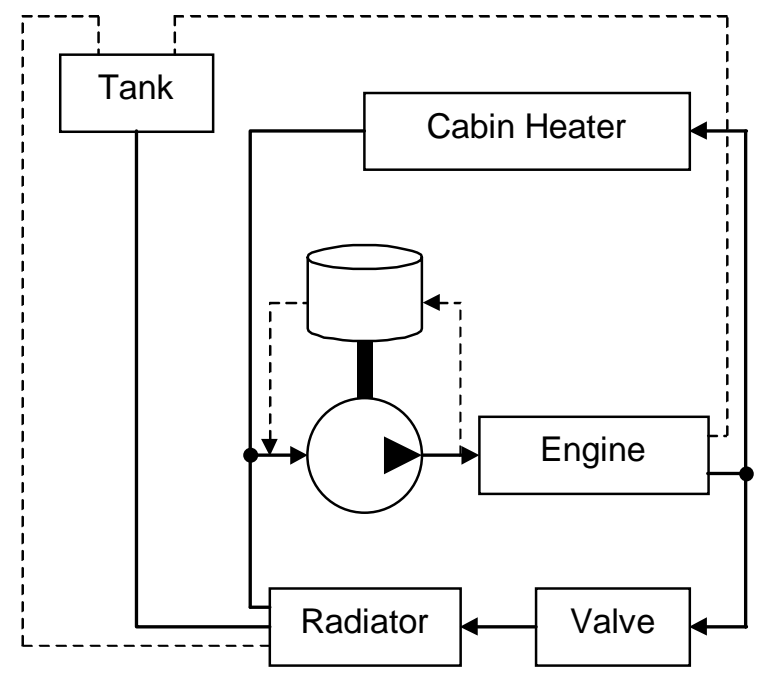

Figure 1 - Schematic of cooling circuit

WATER PUMP - In view of the power draw it was important that hydraulic efficiency be maximised. This is also recognized as an issue with mechanical pumps and Airtex has developed an advanced automotive impeller and volute design system. The system is able to modify the theoretical data to automotive applications by using actual test results gained over a number of years and from more than one source.

This has produced major improvements in pump efficiency and the ability to rapid prototype products; a full 3D-impeller and volute design can be generated and samples produced within 3 days.
An important aspect of electric pumping is that there is no need to compromise the hydraulic design, as it is no longer linked to engine speed. Thus cavitation, a common problem in conventional arrangements, can easily be avoided. Further, by carefully control of the design it is possible to produce impellers with a flattened output curve (Figure 2), i.e. the pump head difference between open and closed thermostat does not affect the heater throughput as much as a conventional design would. This allows a simpler design of flow diverter valve to be used.

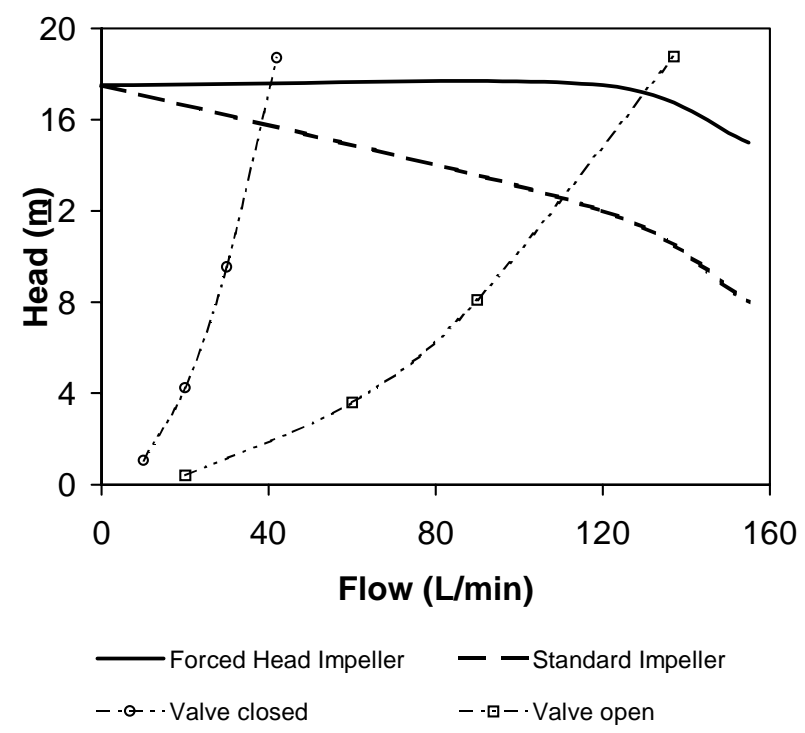

Figure 2 - Forced head impeller characteristic

MOTOR - Several motor concepts were considered to drive the water pump.

Switched Reluctance In the early stages of design the switched reluctance motor was considered. This type of machine will have a lower construction cost and a three phase winding type would also provide a 'limp home' facility with one phase disabled. In addition the machine does not require permanent magnets to produce the air gap flux.

Due to its torque per unit volume the machine is slightly heavier than a brushless DC motor, at present there is a distinct noise problem due to drive and salient pole technology. The latter may reduce with advances in design but at present it does cause concern. These machines also have very small radial air gaps typically 0.25 to $0.3 \mathrm{~mm}$, thus making a water cooled construction, without a dynamic seal, impractical with the normal debris found in an automotive cooling circuit. Increasing the air gap the greatly reduces the efficiency of this type of machine to below $40 \%$ for the complete system. When compared with a brushless DC machine the efficiency is generally lower, and to achieve the 'limp 
home' facility the switched reluctance will require 6 input power leads to maintain the isolated phase relationship.

However developments in this type of motor will be closely monitored and if the technology improves will be considered for future products.

Brushless DC As a result of customer surveys, it was clear that having a product without a dynamic hydraulic shaft seal was highly desirable. Typically on a mechanical water pump, seal failures account for over $90 \%$ of warranty issues. This coupled with the need to cool the motor to cope with under bonnet temperatures lead to a 'wet motor' design.

The size of the debris in an automotive cooling system dictated the size of radial air gap that was required. Brushless DC machines can run at an efficiency of up to $94 \%$ with radial air gaps of $2 \mathrm{~mm}$. Thus ensuring debris in the cooling system does not cause the rotor to seize. The overall efficiency for the complete system, including the drive is in the order of $83 \%$.

Compared to switched reluctance, this type of machine runs quietly under all speed conditions, with improved response times due to high torque and low rotor inertia. In addition the drives required to control this type of machine are well proven. In conclusion, the brushless DC motor has advantages in a number of areas and is capable of leading to a production feasible design.

VOLTAGE CONSIDERATIONS - Although the motor/controller system can be designed to use 12-volt power the current draw is high. This increases losses and requires larger components. With the advent of 42volt vehicle electrics high power applications will become more common. With these factors in mind the decision was taken to prototype a 42-volt motor/controller system. The electrical system was modified to provide 42-volt electrics in addition to the standard 12-volt system.

DIVERTER VALVE - The function of the diverter valve is to control flow to the vehicle radiator and by implication to the heater. When cooling is required the valve opens to allow flow to be split between the heater matrix and the radiator. At other times it should remain closed to prevent undesirable heat loss to the radiator. Due to the forced head impeller design the heater flow rate is less affected by system resistance, allowing a simple one degree of freedom valve to be used. During warm up and operation in cold climates all available heat is required to warm up the engine and passenger compartment. To enable this a very low leakage rate is specified for the valve when it is in its closed position. When the valve is fully open, in conditions requiring large heat rejection rates, the resistance to flow must be low to reduce wasted hydraulic power. Conventional thermostats can contribute as much as $30 \%$ to the total cooling system resistance. When moving from closed to open the valve must be controllable to avoid sudden rushes of cold water from the radiator to the engine. The valve should also failsafe (open), require low operating power, be free from dynamic seals (to avoid potential leaks) and be small, light and inexpensive. It is a demanding requirement. Several prototype arrangements have been developed and will be detailed in a forthcoming paper.

\section{CONTROL STRATEGY}

AIMS - The effectiveness of any integrated cooling scheme depends to a great extent upon the control strategy employed. This project adopts a relatively simple strategy for controlling pump speed, radiator diverter valve position and radiator fan on/off. The strategy was conceived with the following criteria in mind:

1. During warm up only a nominal flow is circulated in order to keep engine temperatures even, but no cooling work is required.

2. If the cabin heater is required during warm-up then pump flow must be stepped up to provide the desired flow rate through the heater circuit.

3. During fully warmed-up steady state operation the system should use minimal pump flow to achieve the desired heat rejection from the engine.

4. Use of the radiator fan should be limited to below a defined road speed.

5. Run-on capability after key-off is included to allow control of heat soak.

6. Flow through the cab heater must not exceed an upper bound to avoid risk of over pressurizing the heater matrix. It should also not fall below a lower bound when cabin heating is required in order to achieve satisfactory heat transfer rates.

STRATEGY - Due to the production-oriented nature of this system, the choice of feedback sensors is limited to engine coolant and block temperatures, and possibly valve position and pump speed. A control strategy has been designed around a minimal configuration of sensors; the strategy uses 2 independent PID plus feedforward loops to control the engine temperature. Loop 1 (see Figure 3) regulates coolant inlet temperature to a setpoint by modulation of the valve position and fan activation. The radiator fan activation is enabled only when the vehicle speed falls below the threshold, as the fan can actually degrade airflow over the radiator at speed. Loop 2 regulates coolant outlet temperature to a setpoint by modulation of the pump speed (Figure 4).

The coolant inlet and outlet temperature setpoints are scheduled against speed and load using 2-D look-up tables, giving the flexibility to operate (for example) at elevated temperature at part load and cooler under full load. These set point tables may be manipulated to achieve the optimum emissions, fuel consumption and performance trade-off. The controller gains can be scheduled, as can the saturation limits on the individual $\mathrm{P}, \mathrm{I}$ and $\mathrm{D}$ terms and the total controller output. Feedforward is applied using 2-D look-up tables, the inputs to which are vehicle speed and load. Vehicle speed is used as opposed to engine speed as it implies 
the level of cooling power available at the radiator. The cabin heater demand is also fed-forward to the pump speed control loop in order to take account of cabin heat requirements within the strategy.

IMPLEMENTATION - The strategy was designed using MATLAB/Simulink, which allowed initial testing with a circuit simulation (described below). The strategy can be rendered as $\mathrm{C}$ code and run on any convenient hardware. The controller selected for the prototype vehicle is an automotive engine control unit derived from racing systems. It has much more power and connectivity than required to ensure flexibility at the prototype stage. Production solutions would be included in the existing engine control strategy.

\section{SYSTEM SIMULATION AND RESULTS}

Previous work $[5,6]$ has suggested that a lumped parameter model of the modified engine cooling system would predict the behavior of the system sufficiently accurately for a control study. Such a simulation was built in MATLAB/Simulink and used to test the design of the system and controller as well as to allow initial setting of the gain terms in the PID control loops. It was built up in a modular format to allow easy re-organization of the system, comprising of hose models connecting the individual components.

Hydraulic modeling of the system is executed as follows: component pressure-flow characteristics (for the engine block, valve, radiator, cabin heater and pump) were collated from empirical data from the component manufacturers and stored in look-up tables. Pressures in connecting pipelines were calculated from the equation for continuity of volume, given the volume of fluid entering and leaving the pipe via components at either end:

$$
P=\frac{B}{V} \int \sum Q_{i} d t+P_{0}
$$

where

$$
\begin{array}{ll}
P & =\text { Line pressure }[\mathrm{Pa}] \\
B & =\text { Fluid bulk modulus }[\mathrm{Pa}] \\
V & =\text { Pipe volume }\left[\mathrm{m}^{3}\right] \\
Q_{i} & =\text { Flow through the ith port }\left[\mathrm{m}^{3} / \mathrm{s}\right] \\
P_{0} & =\text { Initial pressure }[\mathrm{Pa}]
\end{array}
$$

A calculation of frictional pressure loss is also carried out where appropriate, using Blasius' approximation of the friction factor.

Heat transfer is modeled as follows: the engine block model generates heat related by an empirical look-up table to the road power. The mean temperature of the block is calculated and is used to deduce the amount of energy imparted to the fluid and hence the fluid temperature. Both materials use the energy equation to derive their temperature. It is assumed that the fluid temperature at engine outlet is equal to that at the cabin heater and radiator inlets. In both these components heat transfer is calculated from empirical effectiveness data, giving their outlet temperatures. The two cool flows are mixed at the pump inlet using the energy equation to derive the engine inlet temperature. The header tank is modeled as an ideal gas volume and a fluid volume.

Note the important simplifications that have been made; fluid viscosity does not change as a function of temperature, heat transfer from the engine to the fluid and from the fluid to the cabin heater and radiator are large in comparison to other components (all other heat fluxes are small and are ignored), gravitational effects and fluid inertia are ignored and air release and cavitation are not modeled.

Simulations of the European drive cycle (ECE15 + EUDC), motorway and hill climbing have been carried out. Figure 5 shows results of European drive cycle simulations of a standard cooling system with a mechanically driven pump and wax pellet thermostat (left) and the modified system using the electric pump and valve (right). It can clearly be seen that the electric system controls engine temperatures to higher levels, due to the higher set points that have been defined. The fluctuations in engine inlet and outlet temperatures of the electric system are due to the temperature set point changing as the engine regime changes. Further, it can be seen that pump speeds are generally considerably lower in the electric system, while the valve openings are greater to compensate for the lower coolant flow rate. This helps to further reduce power consumption due to lower hydraulic resistance. The end result is that the hydraulic power consumed in the electrical system is two orders of magnitude smaller than the mechanical system.

The rate of engine warm up is comparable in the two systems, though there is a slight advantage to be had with the electrical system. Reducing the minimum pump flow set by the control strategy could reduce warm-up time further, provided there is no cabin heater demand as shown in Figure 6. The allocation of scarce heat resources between engine and cabin heater during warm-up is a difficult priority to define. 


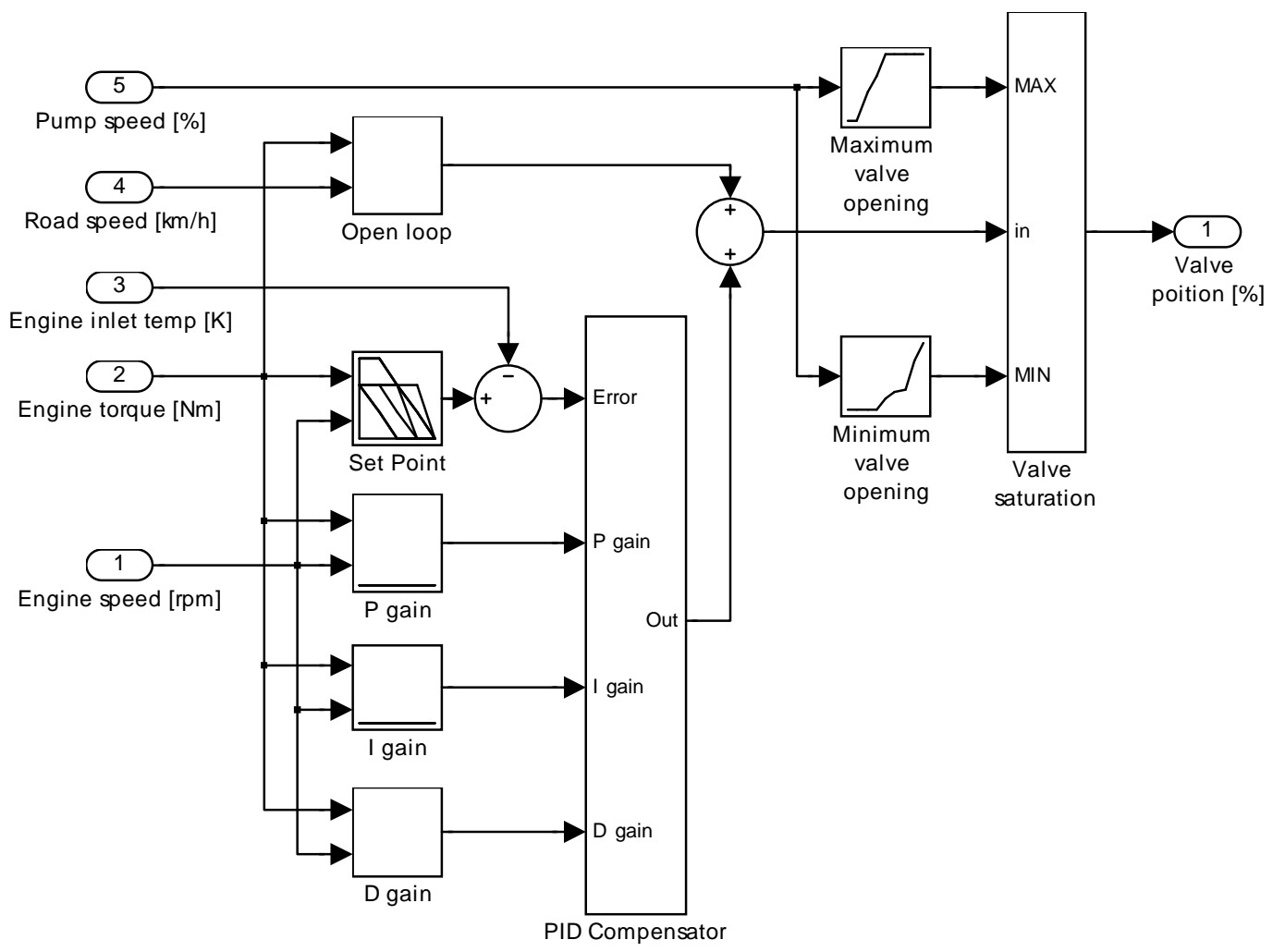

Figure 3 - Control Loop 1, Coolant inlet temperature to Valve position

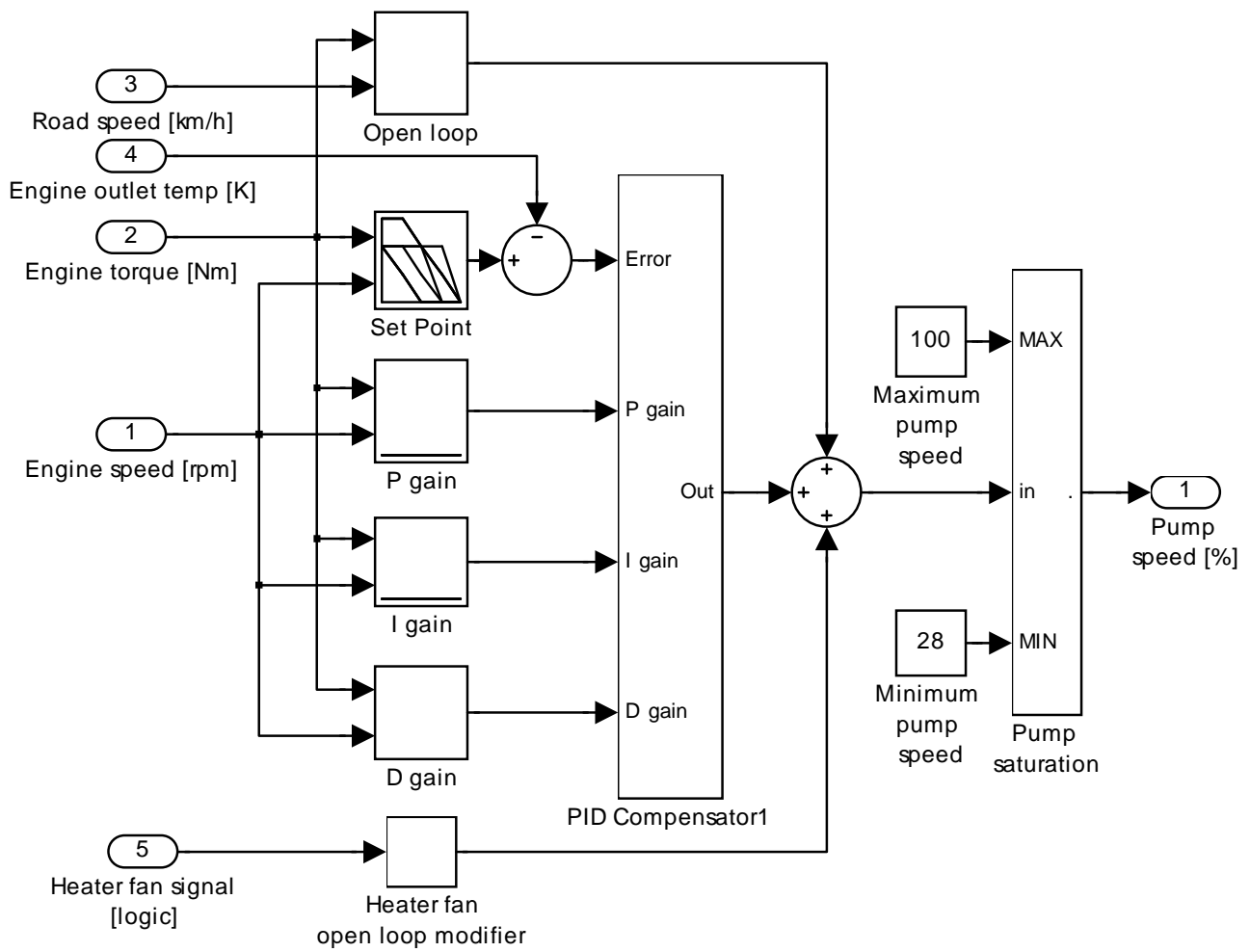

Figure 4 - Control loop 2, Coolant outlet temperature to pump demand 
(A) Mechanical Cooling system
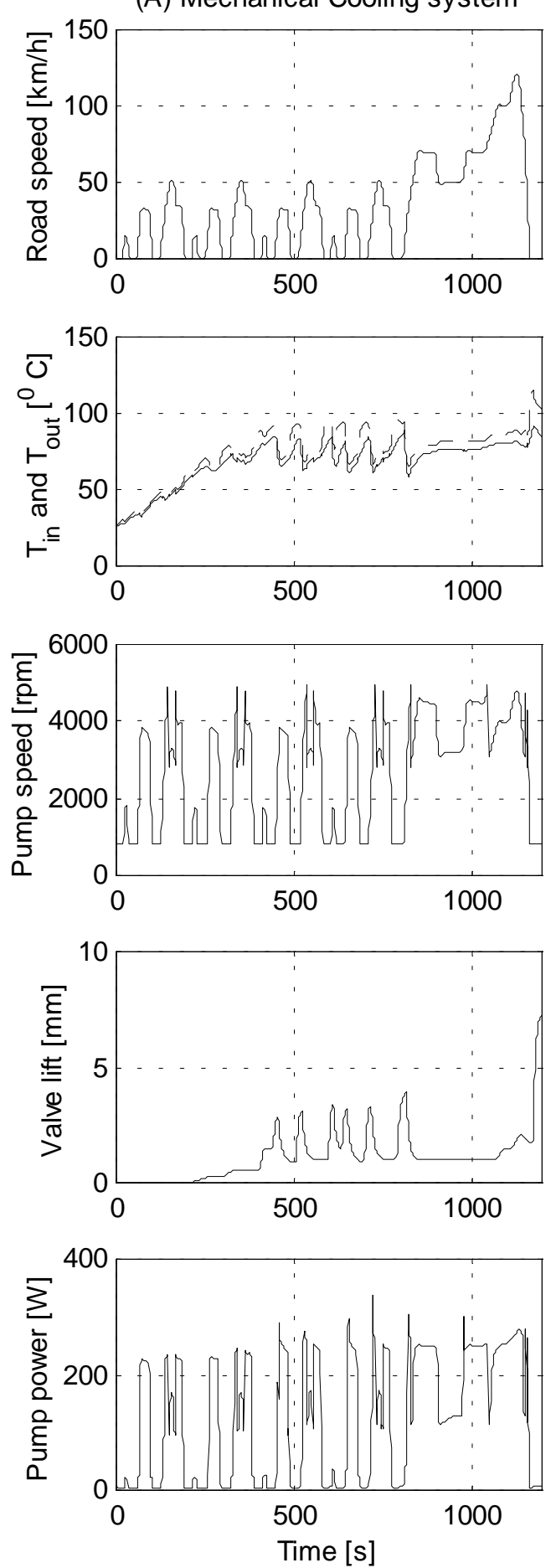

(B) Electrical Cooling system
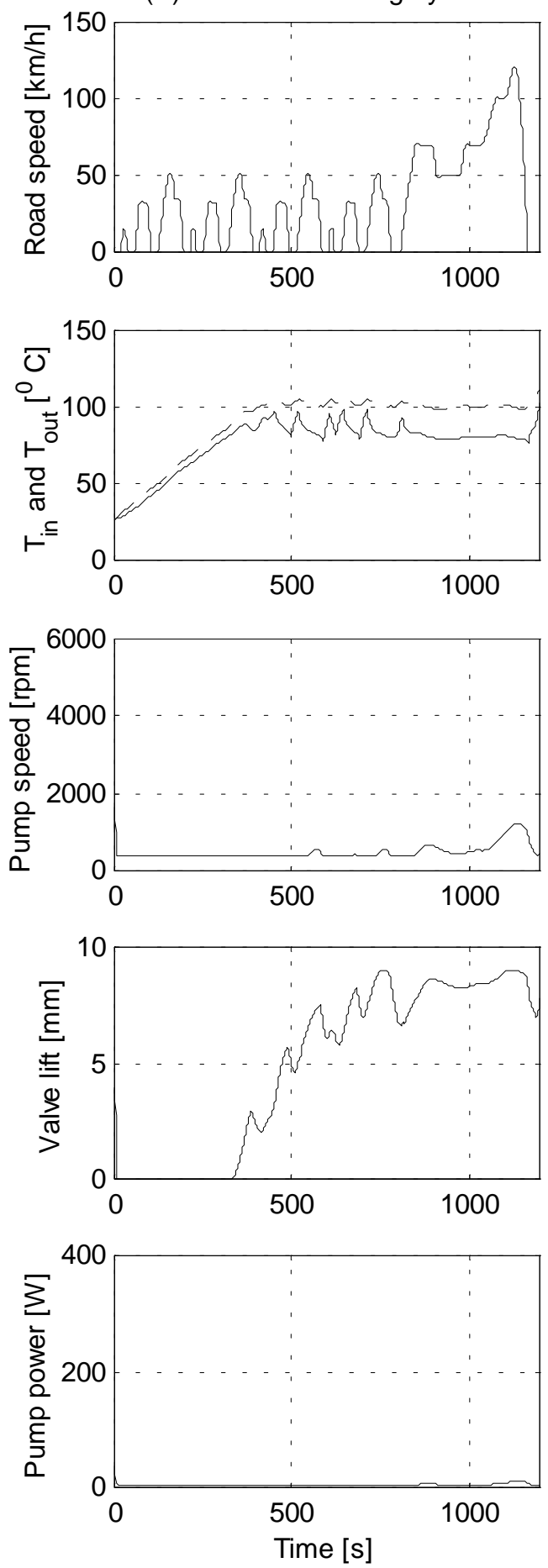

Figure 5 - Plots of system response for the mechanical cooling system (A) and electrical system (B). 


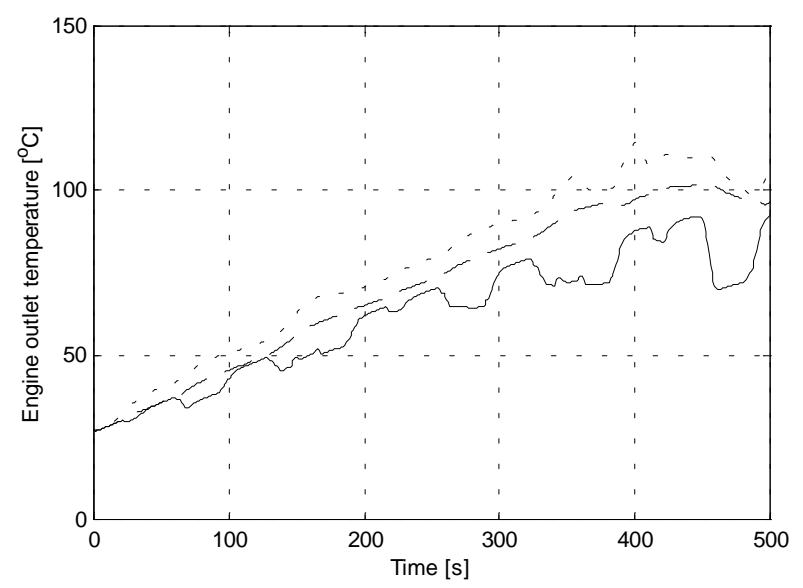

Figure 6 - Warm up times for the mechanical system (bottom) electrical system (middle) and electrical system with no heater demand (top).

\section{CONCLUSION}

A prototype cooling system has been developed which uses a coordinated control strategy to achieve precise control of engine coolant temperature and heat rejection regime using minimum flow rates. The advanced impeller design allows a simplified valve to control flow to the heater and radiator. The simple control strategy described allows great scope for optimization of the system behavior and does not require separate regimes for warm-up and continuous running. Numerical simulations of the system and controller demonstrate a considerable reduction in pump power consumption whilst maintaining good control of coolant temperatures. Increased engine temperatures will lead to reductions in fuel consumption and emissions.

On-going work includes testing a prototype vehicle equipped with the system as described, optimization of the control strategy and assessment of several different valve designs.

Integrated cooling system design as detailed here paves the way for the large-scale introduction of nucleate boiling regimes in passenger vehicles, providing a yet greater saving in pump power and more compact component design.

\section{ACKNOWLEDGMENTS}

The authors would like to thank Dave Blight at Airtex Products Ltd. for all the assistance given during the project documented in this paper.

\section{REFERENCES}

1. Robinson K, Campbell NAF, Hawley JG, Tilley DG. "Review of Precision Engine Cooling". SAE paper 1999-01-0578 (990578). 1999.

2. Einaudi G, Mortara W. "Engine Cooling Electronic control system". SAE 885085. 1988.

3. Ap NS, Golm NC. "New concept of engine cooling system (NewCool)". SAE 971775

4. Ap NS, Maire A, Porot P, Menegazzi P, Souidi F, Devehat CL, Godeau D, Olivier P, Vinot JB, Vincens G. "New components development for new engine cooling system". VTMS 24-26 May 1999, C543/047/99, Cooling Systems. 1999.

5. Sidders JA \& Tilley DG. "Optimising cooling system performance using computer simulation". VTMS 3, Indianapolis, USA, 19-22 May, 1997, 219-230. 1997.

6. Tomlinson SP, Hogan PA \& Burrows CR "Computer simulation of vehicle cooling systems ASME Int ME '94 Congress \& Exposition, Paper No. Control GT94-117 Session FPST-2, Chicago, USA, 6-11 November, 1994.

\section{CONTACT}

Dr Chris Brace

Lecturer in Automotive Engineering

University of Bath

Department of Mechanical Engineering

BA2 7AY

Tel: $\quad+44(0) 1225826731$

Fax: $\quad+44(0) 826928$

email: enscjb@bath.ac.uk 